\title{
Aldehyde dehydrogenase activity is necessary for beta cell development and functionality in mice
}

\author{
Vivian Anastasiou ${ }^{1,2}$ - Elpiniki Ninou ${ }^{3}$ - Dimitra Alexopoulou ${ }^{4} \cdot$ Julia Stertmann $^{1,2,5}$. \\ Andreas Müller ${ }^{1,2}$ • Andreas Dahl ${ }^{4}$ - Michele Solimena ${ }^{1,2} \cdot$ Stephan Speier $^{1,2,5}$. \\ Ioannis Serafimidis ${ }^{3}$ - Anthony Gavalas ${ }^{1,2,3,5}$
}

Received: 17 July 2015 / Accepted: 22 September 2015 / Published online: 31 October 2015

(C) The Author(s) 2015. This article is published with open access at Springerlink.com

\begin{abstract}
Aims/hypothesis Pancreatic beta cells maintain glucose homeostasis and beta cell dysfunction is a major risk factor in developing diabetes. Therefore, understanding the developmental regulatory networks that define a fully functional beta cell is important for elucidating the genetic origins of the disease. Aldehyde dehydrogenase activity has been associated with stem/progenitor cells and we have previously shown that Aldh $1 b 1$ is specifically expressed in pancreas progenitor pools. Here we address the hypothesis that Aldh1b1 may regulate the timing of the appearance and eventual functionality of beta cells.
\end{abstract}

Vivian Anastasiou and Elpiniki Ninou contributed equally to this work.

Electronic supplementary material The online version of this article (doi:10.1007/s00125-015-3784-4) contains peer-reviewed but unedited supplementary material, which is available to authorised users.

Ioannis Serafimidis

iseraf@bioacademy.gr

$\square$ Anthony Gavalas

anthony.gavalas@mailbox.tu-dresden.de

1 Paul Langerhans Institute Dresden of Helmholtz Center Munich at the University Clinic Carl Gustav Carus of TU Dresden,

Fetscherstrasse 74, 01307 Dresden, Germany

2 DZD - German Centre for Diabetes Research, Germany, http://www.dzd-ev.de/en

3 Developmental Biology Laboratory, Biomedical Research Foundation of the Academy of Athens, Soranou Ephessiou 4, Athens 11527, Greece

4 Deep Sequencing Group SFB655, BIOTEChnology Center (BioZ), TU Dresden, Dresden, Germany

5 DFG-Center for Regenerative Therapies Dresden (CRTD), Faculty of Medicine, TU Dresden, Dresden, Germany
Methods We generated an Aldh1b1-knockout mouse line $\left(\right.$ Aldh $\left.1 b 1^{\text {tmllacZ }}\right)$ and used this to study pancreatic development, beta cell functionality and glucose homeostasis in the absence of Aldh1bl function.

Results Differentiation in the developing pancreas of Aldh1b1 $1^{\text {tmllacZ }}$ null mice was accelerated. Transcriptome analyses of newborn and adult islets showed misregulation of key beta cell transcription factors and genes crucial for beta cell function. Functional analyses showed that glucose-stimulated insulin secretion was severely compromised in islets isolated from null mice. Several key features of beta cell functionality were affected, including control of oxidative stress, glucose sensing, stimulus-coupling secretion and secretory granule biogenesis. As a result of beta cell dysfunction, homozygous mice developed glucose intolerance and age-dependent hyperglycaemia.

Conclusions/interpretation These findings show that Aldh1b1 influences the timing of the transition from the pancreas endocrine progenitor to the committed beta cell and demonstrate that changes in the timing of this transition lead to beta cell dysfunction and thus constitute a diabetes risk factor later in life.

Gene Expression Omnibus (GEO) accession: GSE58025

Keywords Aldehyde dehydrogenase $\cdot$ Beta cell development $\cdot$ Beta cell dysfunction $\cdot$ Beta cell transcriptome . Diabetes risk factor $\cdot$ Hyperglycaemia $\cdot$ Insulin secretion
Abbreviations
ALDH Aldehyde dehydrogenase
AMPK AMP-activated protein kinase
AMY Amylase complex
C-PEP C-peptide
DBA Dolichos biflorus agglutinin 


$\begin{array}{ll}\text { dpc } & \text { Days post coitum } \\ \text { GCG }^{+} & \text {Glucagon-positive } \\ \text { GLP1R } & \text { Glucagon-like peptide-1 receptor } \\ \text { GSIS } & \text { Glucose-stimulated insulin secretion } \\ \text { IPGTT } & \text { Intraperitoneal glucose tolerance test } \\ \text { IPITT } & \text { Intraperitoneal insulin tolerance test } \\ \text { IPPTT } & \text { Intraperitoneal pyruvate tolerance test } \\ \text { NGN3 } & \text { Neurogenin 3 } \\ \text { NKX6.1 } & \text { NK6 homeobox 1 } \\ \text { P1 } & \text { Postnatal day 1 } \\ \text { PDX1 } & \text { Pancreatic and duodenal homeobox 1 } \\ \text { PH3 } & \text { Phosphohistone-H3 } \\ \text { ROS } & \text { Reactive oxygen species } \\ \text { SG } & \text { Secretory granule } \\ \text { SOM } & \text { Somatostatin }\end{array}$

\section{Introduction}

Extensive genome-wide association studies have identified over 80 genomic susceptibility loci for type 2 diabetes. The majority of the discovered risk variants have been linked to beta cell dysfunction rather than to insulin resistance [1]. Thus, elucidating the developmental regulatory networks defining a fully functional beta cell is important for understanding the genetic origins of the disease and deriving mature beta cells from stem cells.

All pancreatic cell types are derived from progenitors that emerge at the posterior foregut region of the definitive endoderm and expand to form a branched epithelium surrounded by mesenchyme [2]. Subsequently, acinar progenitors are confined at the tips, while trunk cells become endocrine/duct bipotent progenitors. Neurogenin 3-positive $\left(\mathrm{NGN}^{+}\right)$endocrine progenitors arise in the trunk and migrate into the mesenchyme leaving behind ductal progenitors [3]. The emergence of progenitor pools and differentiated cell types is temporally regulated but the mechanisms implicated are unknown $[3,4]$. After birth, normal beta cell development continues with the maturation of the stimulus-secretion coupling machinery, the enhancement of glucose sensing, the increase in the number of insulin-containing secretory granules (SGs) and the establishment of the appropriate beta cell mass through extensive proliferation. Several transcription factors implicated in progenitor and endocrine specification also play key overlapping roles in the postnatal expansion, maturation and maintenance of adult beta cells. Their expression levels are also important for beta cell functionality [5-12]. Disturbances of the intrauterine milieu can lead to islet defects and diabetes later in life but little is known about the molecular mediators of this effect [13-15].

Aldehyde dehydrogenase (ALDH) activity is increasingly associated with stem/progenitor cells and it is hypothesised that it contributes to the maintenance of the progenitor status [16-19]. Mitochondrial Aldhlb1 is specifically expressed in all pancreas progenitors in the mouse embryo but not in mature endocrine cells. Its expression in the adult is confined to rare centroacinar-like cells with pancreas stem/progenitor characteristics $[18,20]$. Here we addressed the hypothesis that Aldh1b1 may regulate the timing of the appearance and eventual functionality of beta cells.

\section{Methods}

Aldh 1 b $1^{\text {tm } 1 \text { lacz }}$-knock-in mouse strain The Aldh $1 b 1^{\text {tm1(KOMP)Vlcg }}$ ES line (KOMP; UC Davis, CA, USA) was used to generate the Aldh $1 b 1^{\text {tmllacZ }}$ allele (electronic supplementary material [ESM] Fig. 1). Animal maintenance and experimentation were in accordance with international guidelines and subjected to ethics approval from the competent veterinary committees of Athens and TU Dresden. Animals were assigned to experiments randomly on condition of fulfilling the conditions of the experiment (genotype, sex, age) as described, and the scoring/outcome assessment was blind to group assignment.

Fasting glucose measurements and glucose, insulin and pyruvate tolerance tests For the intraperitoneal glucose tolerance test (IPGTT), male mice were fasted for $16 \mathrm{~h}$ overnight and injected intraperitoneally with D-glucose (Sigma-Aldrich, St Louis, MO, USA) at $2 \mathrm{~g} / \mathrm{kg}$. Blood from the tail vein was used to determined glucose level using the Contour XT monitoring system (Bayer, Leverkusen, Germany) and insulin level was determined in the supernatant fraction following clotting using an ultrasensitive mouse insulin ELISA kit (Mercodia, Uppsala, Sweden). Details of the intraperitoneal insulin tolerance test (IPITT) and intraperitoneal pyruvate tolerance test (IPPTT) procedures are provided in ESM Methods.

Immunostaining and morphometric analysis Dissected pancreases were fixed in $4 \% \mathrm{wt} / \mathrm{vol}$. paraformaldehyde and processed for immunofluorescence using standard procedures $[18,21]$. Details of antibodies used and morphometric analyses are provided in ESM Methods.

Islet isolation and functional analyses Islets were isolated from male mice and maintained as described [22]. Standard procedures were used for insulin secretion assays, measurements of intracellular calcium $\left(\left[\mathrm{Ca}^{2+}\right]_{\mathrm{i}}\right)$ changes [23], detection of reactive oxygen species (ROS) [24], ATP measurements [25] and transmission electron microscopy [26]. Details are provided in ESM Methods.

RNA isolation, real-time PCR, RNA Seq and accession numbers Total RNA was prepared using the RNeasy kit (Qiagen, Hilden, Germany), first-strand cDNA preparation, 
real-time PCR and library preparations for RNA sequencing and bioinformatics analyses were done according to standard procedures. Details are provided in ESM Methods. Raw and normalised data were deposited in GEO (www.ncbi.nlm.nih.gov/geo) under accession number GSE58025.

\section{Hormone measurements and liver glycogen content assay}

Pancreatic insulin, proinsulin and glucagon content, as well as liver glycogen content, were assayed as described in ESM Methods.

Western blotting and X-gal staining Details on western blotting and X-gal staining procedures are provided in ESM Methods.

Statistical analyses Statistical significance was determined by Student's $t$ test for two-tailed distributions of unpaired groups. For analyses of wild-type and null mice at different time points (with the exception of gestation time points) twoway ANOVA with Bonferroni post hoc test for differences between means were conducted. The SEM is provided unless otherwise stated and $p<0.05$ was considered significant. For differences in islet size distributions and means, statistical significance was determined using the Wilcoxon rank-sum test and $p<0.001$ was considered significant.
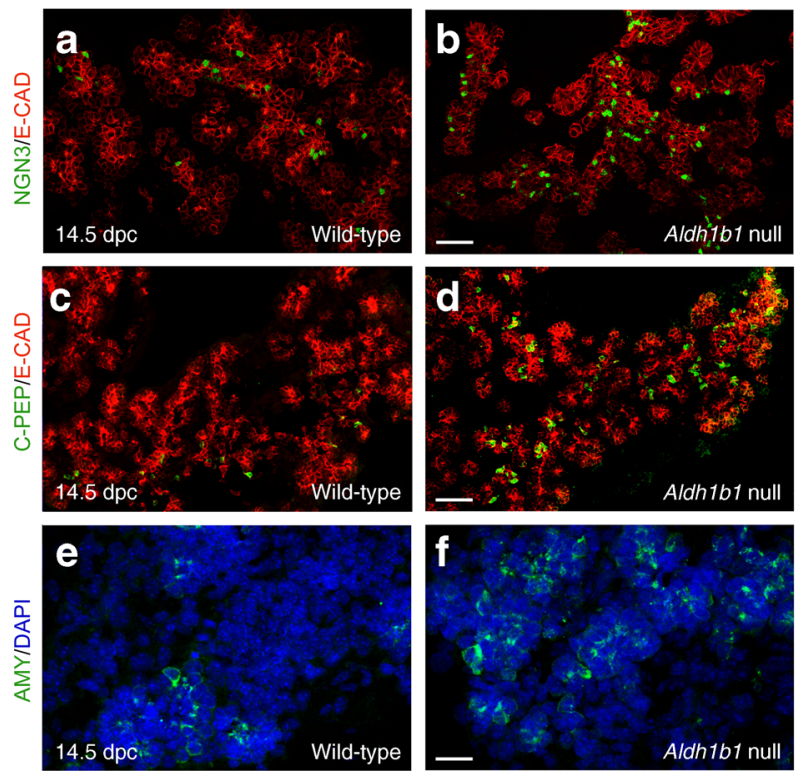

Fig. 1 ALDH1B1 controls timing of commitment and proliferation of embryonic pancreas progenitors and is expressed in nascent beta cells. (a-h) The number of $\mathrm{NGN}^{+}(\mathbf{a}, \mathbf{b}), \mathrm{C}-P E P^{+}(\mathbf{c}, \mathbf{d}), \mathrm{AMY}^{+}(\mathbf{e}, \mathbf{f})$ and $\mathrm{DBA}^{+}(\mathbf{g}, \mathbf{h})$ cells was increased in pancreases of $A l d h 1 b 1^{\text {tmllacZ }}$ null mice compared with wild-type mice. (i, j) Co-expression of ALDH1B1 with newly formed beta cells remains until $15.5 \mathrm{dpc}$ (arrows) but is lost at 16.5 dpc. (k) Quantification of ${\mathrm{C}-\mathrm{PEP}^{+}}^{+}$(squares), $\mathrm{NGN}^{+}$(triangles) signal (DAPI normalised) and number of $\mathrm{PH}^{+}$epithelial (diamonds) cells per islet at $13.5,14.5$ and 15.5 . dpc showed a transient increase (expressed as fold increase compared with wild-type) in Aldh $1 b 1^{\mathrm{tm} 1 \mathrm{lacZ}}$

\section{Results}

Premature lineage commitment during development in the absence of Aldh1b1 expression We generated the Aldh $1 b 1^{\text {tmllacz }}$ mouse line (ESM Fig. $1 \mathrm{a}, \mathrm{b}$ ) and analysed pancreas development in the Aldh $1 b 1^{\text {tmllacZ }}$ null embryos in which $L a c z$ expression recapitulated expression in the pancreas (ESM Fig. $1 \mathrm{c}-\mathrm{h})$.

Early development appeared normal (data not shown) but progenitor differentiation was accelerated during the secondary transition. There was a transient increase in the number of $\mathrm{NGN}^{+}$cells at 13.5 and 14.5 days post coitum (dpc) (Fig. 1a, b, k) and, consistently, the number of C-peptidepositive $\left(\mathrm{C}-\mathrm{PEP}^{+}\right)$cells (but not glucagon-positive $\left[\mathrm{GCG}^{+}\right]$cells, data not shown) was increased in the Aldh $1 b 1^{\text {tm1lacZ }}$ null pancreases (Fig. 1c, d, k). Amylase complex-positive $\left(\mathrm{AMY}^{+}\right)$ acinar cells and duct Dolichos biflorus agglutinin-positive $\left(\mathrm{DBA}^{+}\right)$cells appeared earlier and were more numerous in the Aldh $1 b 1^{\text {tm1lacZ }}$ null pancreases at $14.5 \mathrm{dpc}$ (Fig. 1e-h, 1, m).

The number of epithelial cells in mitosis (Phosphohistone$\mathrm{H}^{+} /$E-cadherin ${ }^{+}$cells) transiently increased in the Aldh $1 b 1^{\text {tmllacZ }}$ null pancreases at $14.5 \mathrm{dpc}$, thus compensating for the accelerated differentiation and maintaining the size of the organ (Fig. 1k and data not shown). Apoptosis levels, detected by immunofluorescence for activated caspase-3,
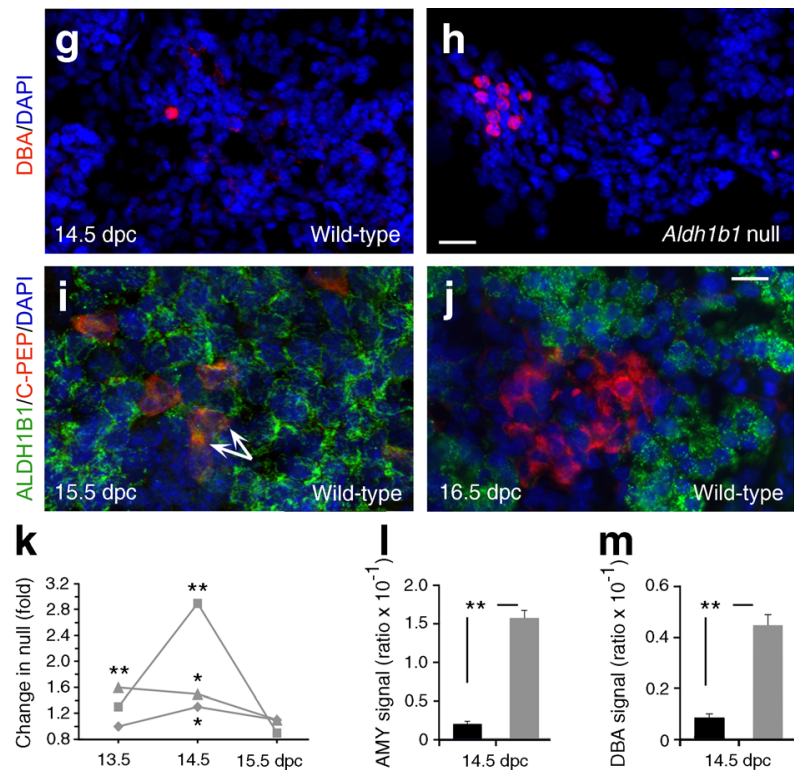

null pancreases. Comparisons were done for the same day. (l, m) Quantification of $\mathrm{AMY}^{+}(\mathbf{I})$ and $\mathrm{DBA}^{+}(\mathbf{m})$ signal (DAPI normalised) at $14.5 \mathrm{dpc}$ showed a strong increase (expressed as ratio over wild-type) in the Aldh $1 b 1^{\text {tmllacz }}$ null pancreases (black bars, wild-type; grey bars, null). Results are from four to six embryos per genotype and per embryonic stage, and values are representative of eight sections per embryonic pancreas spanning the entire organ. $* p<0.05$ and $* * p<0.01$. Scale bars, $50 \mu \mathrm{m}(\mathbf{a}, \mathbf{b}), 100 \mu \mathrm{m}(\mathbf{c}, \mathbf{d}), 20 \mu \mathrm{m}(\mathbf{e}-\mathbf{h})$ and $15 \mu \mathrm{m}(\mathbf{i}, \mathbf{j})$. E-CAD, E-cadherin 
were very low and similar to controls excluding implication of ALDH1B1 in progenitor survival (data not shown).

Expression of the sex determining region Y-box 9 (SOX9), pancreatic and duodenal homeobox 1 (PDX1) and pancreas specific transcription factor 1a (PTF1a) progenitor markers at $14.5 \mathrm{dpc}$ and RNA Seq analysis of 13.5 and $15.5 \mathrm{dpc}$ total pancreases did not detect other significant quantifiable differences between wild-type and Aldh $1 b 1^{\text {tmllacZ }}$ null pancreases, suggesting that only a subset of progenitor cells are affected at successive time points. Careful analysis of ALDH1B1 expres-

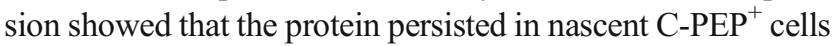
until $15.5 \mathrm{dpc}$ but not later (Fig. 1i, j and data not shown).

Therefore, loss of Aldh $1 b 1$ function resulted in premature differentiation, balanced by increased mitosis, suggesting a dual role for Aldh $1 b 1$ in regulating both timing of commitment and proliferation of progenitors. We then asked whether loss of ALDH1B1 in progenitors and nascent beta cells affected islet patterning and beta cell function.

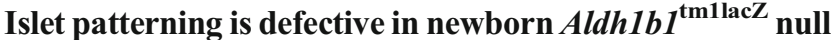
mice Cellular analysis revealed a striking heterogeneity of Aldh $1 b 1^{\text {tml lacZ }}$ null islets at postnatal day 1 (P1). Expression of the transcription factors PDX1 and NK6 homeobox 1 (NKX6.1) [12, 27-30] was homogeneous in control islets whereas a large number of $A l d h 1 b 1^{\text {tmllacZ }}$ null islets showed absent, substantially weaker NKX6.1 expression (47\%) or strongly increased expression (18\%). Some (35\%) showed substantially weaker PDX1 expression compared with controls and co-expression of NKX6.1 and PDX1 within cells of the same islet was not uniform (ESM Fig. 2 a, b, b' and data not shown) $(n=76)$. This was accompanied by variable levels of C-PEP immunofluorescence in the Aldh $1 b 1^{\text {tmllacZ }}$ null P1 pancreases, where $50 \%$ of the islets had either reduced or absent staining compared with controls (ESM Fig. 2c, d, d'). In addition, the number of phosphohistone-H3 $(\mathrm{PH} 3)^{+}$cells was increased by nearly $40 \%$ in the null islets (ESM Fig. $2 \mathrm{f}$ and data not shown). However, Aldh $1 b 1^{\text {tmllacZ }}$ P1 null pancreases had similar weight, beta cell mass, islet size distribution and insulin, proinsulin and glucagon content compared with controls. The relative numbers of alpha, beta and delta cells remained similar (Fig. 4d, ESM Figs 2 e, 3 g-j, 1 and data not shown).

Western blots and RNA Seq data confirmed that Aldh1b1 is not expressed in the islets at postnatal and adult stages [18] (ESM Fig. 2g). Transcriptome comparison of P 1 Aldh $1 b 1^{\text {tmllacz }}$ null and control islets showed deregulation of a substantial number of genes (Fig. 2a, c). This deregulation included repression of several transcription factors with key roles in beta cell maturation and maintenance, such as $P d x 1, N k x 6.1$, Mafa and Mafb (Fig. 2d and ESM Table 1), and misregulation of several genes encoding vesicular and SG proteins (see below).

Taken together these data suggest that $A l d h 1 b 1$ is necessary for proper fetal development of beta cells and the upregulation of key transcription factors.

Islet patterning defects are maintained and expanded in adulthood The murine pancreas undergoes dramatic remodelling during the postnatal period when beta cell mass expands and beta cells acquire the capacity to secrete insulin in response to glucose [31, 32]. Heterogeneity in Aldh $1 b 1^{\text {tmllacZ }}$ null islets persisted in early adults at 6 weeks of age. Nearly one-third of null islets $(30 \%)$ showed substantially lower or absent expression of both PDX1 and NKX6.1, one-third (37\%) consisted of a mixture of $\mathrm{PDX}^{+}$and NKX6.1 $1^{+}$cells and the remaining $33 \%$ had normal PDX1 and NKX6.1 expression $(n=123)$ (Fig. 3a-c, k). Changes in the expression of these genes have been associated with increased numbers of $\mathrm{GCG}^{+}$and somatostatin $(\mathrm{SOM})^{+}$cells $[12,25]$. Accordingly, many null islets contained supernumerary $\mathrm{GCG}^{+}$and $\mathrm{SOM}^{+}$cells and often had disrupted architecture (Fig. 3d-g). There was no apparent interconversion among endocrine cells since we were unable to detect any C-PEP ${ }^{+} / \mathrm{GCG}^{+}$or insulin-positive (INS) ${ }^{+} / \mathrm{SOM}^{+}$ cells (data not shown). Furthermore, $50 \%$ of the islets, particularly larger ones, had low or even absent C-PEP and INS
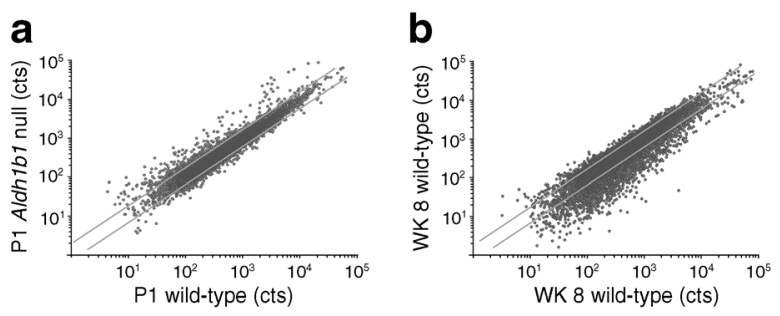

Fig. 2 Islet transcriptome analysis at P1 and week 8 (WK 8). (a, b) Scatter plots of normalised gene transcription counts (cts) of Aldh $1 b 1^{\text {tmllacZ }}$ null islets vs wild-type (WT) islets at P1 (a) (Pearson's $r=0.63$ ) and WK 8 (b) (Pearson's $r=0.56$ ). Diagonal lines represent regulation cut-offs at 0.6 - and 1.6-fold. (c) Proportional Venn diagram of the genes misregulated in Aldh $1 b 1^{\text {tmllacZ }}$ null islets at $\mathrm{P} 1$, WK 8 or both (overlap). In the overlap,
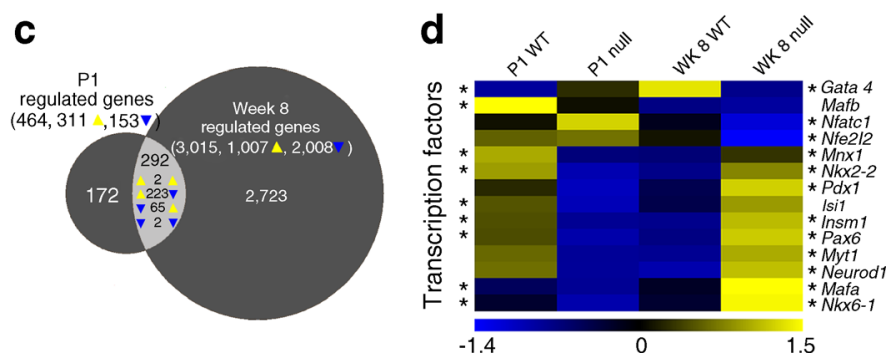

the direction of regulation at P1 (left) or WK 8 (right) is shown for genes regulated at both time points. (d) Heat map of relative expression values ( $z$ scores) of transcription factors in $A l d h 1 b 1^{\text {tmllacZ }}$ null and control pancreases at P1 and $\mathrm{WK} 8 .{ }^{*} p_{\text {adj }} \leq 0.1$ : at the left side of the heat map $*$ refers to comparisons at $\mathrm{P} 1$ whereas at the right side it refers to comparisons at WK 8 

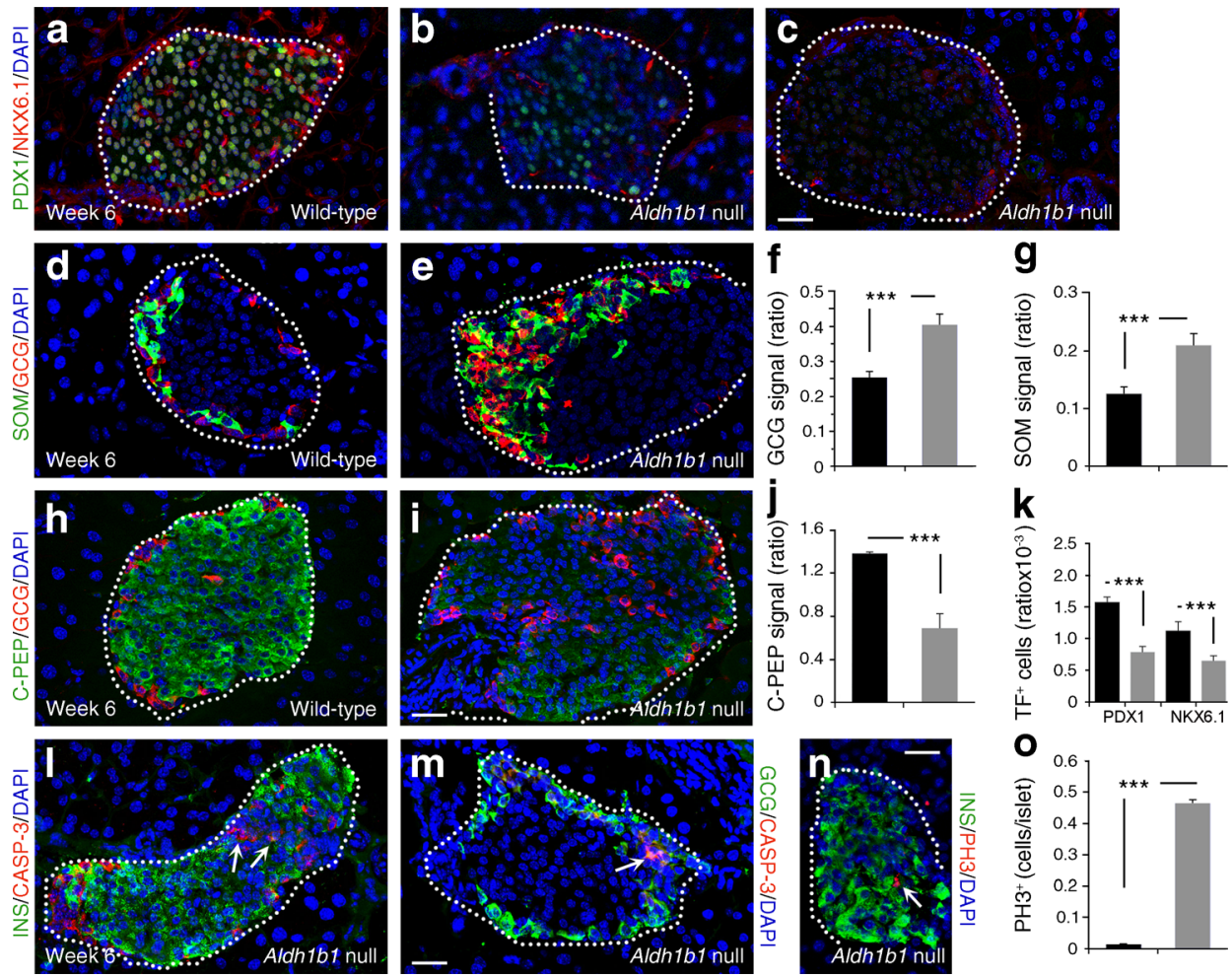

Fig. 3 Islet patterning defects in $A l d h 1 b I^{\text {tmllacZ }}$ null young adult mouse islets. (a-c, h-i) Substantially lower (b) or absent (c) PDX1, NKX6.1 $(\mathbf{a}-\mathbf{c})$ and C-PEP $(\mathbf{h}, \mathbf{i})$ expression in Aldh $1 b 1^{\text {tmllacZ }}$ null islets. (d-g) Quantitative analysis of glucagon (GCG) and SOM (d, e) signal per islet (expressed as ratio of signal over DAPI signal) shows that the signal is increased by 60 and $65 \%$, respectively (f, g), in Aldh $1 b 1^{\text {tm } 1 \text { lacZ }}$ null islets (black bars, wild-type; grey bars, null). (j, k) Quantitative analysis of C-PEP signal (j) and PDX1 $1^{+}$, NKX6. $1^{+}$cells (k) per islet (expressed as ratio of signal over DAPI signal) shows that their expression is significantly reduced in Aldh $1 b I^{\text {tmllacZ }}$ null islets (black bars, wild-type; grey

immunoreactivity while maintaining normal GLUT2 and glucagon-like peptide-1 receptor (GLP1R) expression (Fig. 3h-j and ESM Fig. 4 a-d). Null islets showed ectopic caspase-3 immunoreactivity in both normally and weakly C-PEP ${ }^{+}$null islets (Fig. 31, m) and persistent mitotic activity, mostly in those exhibiting low C-PEP staining (Fig. 3n, o), thus maintaining beta cell mass and median islet size (Fig. $4 \mathrm{~d}$ and ESM Fig. 3a). Heterogeneity persisted at week 20, particularly concerning low C-PEP and NKX6.1 immunofluorescence, mostly in larger islets (ESM Fig. $4 \mathrm{e}-\mathrm{h}$ ).

These findings showed that defects and heterogeneity in islet patterning persisted into adulthood and to determine their extent we compared the transcriptome of Aldh $1 b I^{\text {tmllacZ }}$ null and control islets isolated at week 8 . The number of misregulated genes had now expanded more than sixfold (Fig. 2b, c) and gene ontology analyses suggested that key components of beta cell function were affected (see below). Strikingly, expression of most transcription factors necessary to maintain islet functionality, with the notable exception of the downregulation of $N f e 2 l 2$ ( $N r f 2$ ), a gene protecting beta bars, null). (l, m) Aldh $1 b 1^{\text {tmllacZ }}$ null islets showed increased levels of apoptosis as indicated by double immunofluorescence for caspase-3 (CASP-3) and either insulin (INS) (l) or GCG (m) (arrows). (n, o) Immunofluorescence for $\mathrm{PH} 3$ (n) indicated that mitotic activity was 50-fold higher (o) in Aldh $1 b 1^{\text {tmllacZ }}$ null islets (black bars, wild-type; grey bars, null). Results are from three to five animals per genotype, and values are representative of scoring at least 50 islets spanning the entire pancreas of each animal. Values are mean \pm SEM. $* * * p<0.001$ for indicated comparisons. Scale bars, $25 \mu \mathrm{m}(\mathbf{a}-\mathbf{e}, \mathbf{h}, \mathbf{i}, \mathbf{l}-\mathbf{n})$. TF, transcription factor

cells from oxidative stress [33], was upregulated, suggesting an effort towards functional compensation (Fig. 2d and ESM Table 1). Consistent with the increased mitosis rates, expression of several cell cycle and mitosis-associated genes was altered in the Aldh $1 b 1^{\text {tmllacZ }}$ null islets (ESM Fig. 5a and ESM Table 2). Continued mitosis in the islets resulted in a 3.6-fold expansion of the beta cell mass and a twofold increase in the median islet size in Aldh $1 b 1^{\text {tmllacZ }}$ nulls by week 20 (Fig. 4a-d, ESM Fig. 2e and ESM Fig. 3a).

These findings showed that early defects persisted and expanded in the islets of Aldh $1 b 1^{\text {tmllacZ }}$ null mice, suggesting impaired functionality.

Null mice are glucose intolerant and develop age-dependent hyperglycaemia To establish whether these molecular defects compromised glucose homeostasis we first determined blood glucose levels following overnight fasting of 6- to 52-week-old mice. From 12 weeks onwards $A l d h 1 b 1^{\text {tmllacZ }}$ null mice developed hyperglycaemia, which accelerated with age (Fig. 4e) [34]. IPGTTs showed that the onset of hyperglycaemia was 

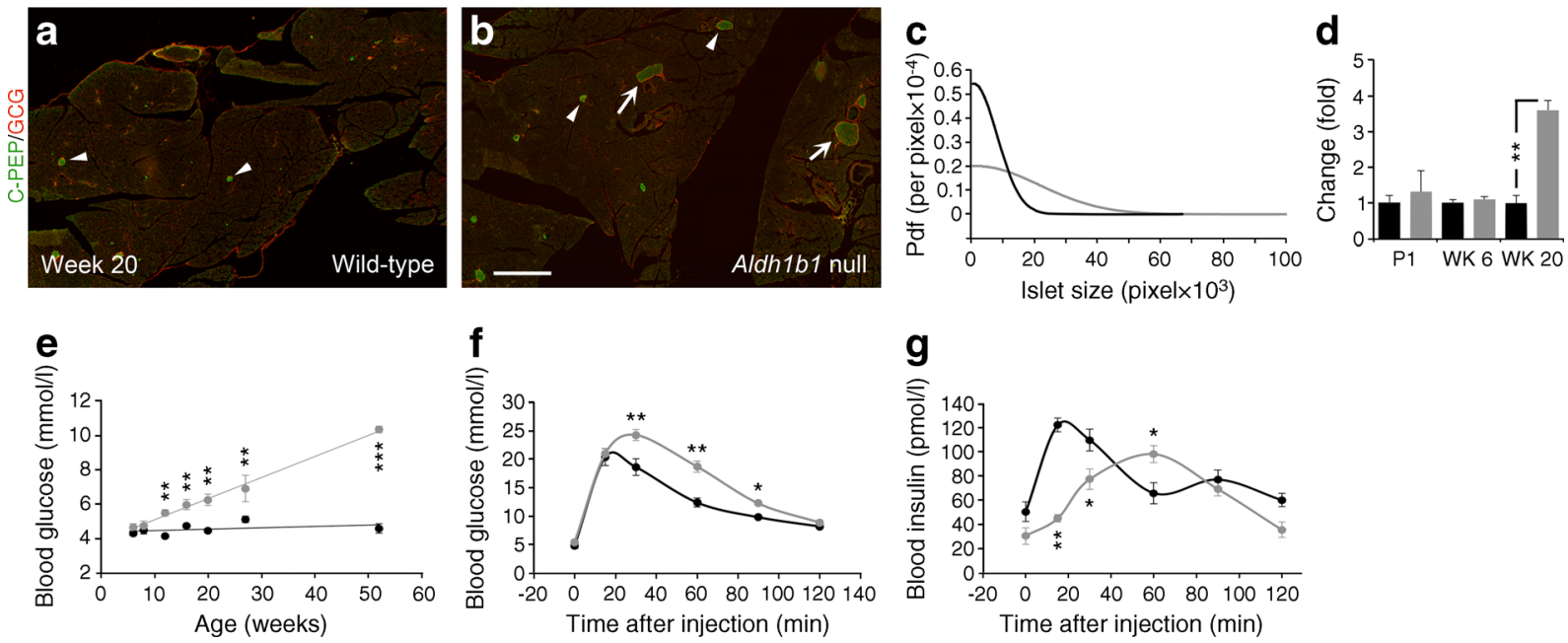

Fig. 4 Aldh $1 b 1^{\text {tmllacZ }}$ null mice have larger islets but are glucose intolerant and develop age-dependent hyperglycaemia. (a, b) Double immunofluorescence for C-PEP and glucagon (GCG) indicated the presence of both normal-sized islets (arrowheads) and significantly larger islets (arrows) in Aldh $1 b 1^{\text {tmllacz }}$ null mice compared with wild-type mice. (c) Morphometric analysis and plotting of the islet size probability density function (pdf) illustrates the significantly larger Aldhlb ${ }^{\text {tmllacZ }}$ null median islet size $(3,223)$ compared with the wild-type $(1,413)$ (black line, wild-type; grey line, null) at week 20 . Sizes are expressed in pixels $(100 \mu \mathrm{m}=135$ pixels $)$. Differences in the distribution are significant $(p<0.001)$. (d) Beta cell mass differences are negligible at P1 and week 6 (WK 6) but there is a 3.6-fold increase in the beta cell mass of the Aldh $1 b 1^{\text {tmllacZ }}$ compared with that of wild-type at week 20 (WK 20) (black bars, wild-type; grey bars, null). ${ }^{* *} p<0.01$ for the indicated

comparison. (e) Blood glucose levels after overnight fasting in 6- to 52-week-old mice showed that Aldhlbl ${ }^{\text {tmllacZ }}$ nulls gradually develop hyperglycaemia (black line, wild-type; grey line, null) $(n=8-20)$. (f) Aldh $1 b 1^{\text {tmllacZ }}$ nulls show a significant delay in blood glucose clearance during IPGTT at week $8(n=8,7)$ (black line, wild-type; grey line, null). (g) Acute insulin secretion during IPGTT is impaired at WK 8 in Aldh $1 b 1^{\text {tm1lacZ }}$ null mice compared with wild-type mice $(n=5)$ (black line, wild-type; grey line, null). Results in (a-d) are from three animals per genotype and per age group, and values are representative of 25 sections spanning the entire pancreas of each animal. Results in $(\mathbf{e}-\mathbf{g})$ are from the indicated number of animals $(n)$ per genotype. Values are mean \pm SEM. ${ }^{*} p<0.05, * * p<0.01$ and $* * * p<0.001$, Aldh $1 b 1^{\text {tmllacZ }}$ null vs wild-type. Scale bar, $1.5 \mathrm{~mm}$

preceded by reduced glucose tolerance and significant delay in acute insulin secretion in young adult $A l d h l b I^{\text {tmllacZ }}$ null mice. The first-phase response in the $A l d h l b 1^{\text {tmllacZ }}$ null mice took nearly three times as long to peak without reaching control levels and a second-phase response was absent (Fig. 4f, g). Reduced glucose tolerance was further exacerbated at week 20 and acute insulin secretion was equally weak at week 20 (ESM Fig. 3b, c).

Hormone levels were not reduced at week 8 or week 20 in Aldh $1 b 1^{\text {tmllacZ }}$ null pancreases and pancreas weight was similar to that in wild-type controls (see above and data not shown). In fact, there was a transient increase in insulin and proinsulin content as well as a 2.6-fold increase in glucagon content in the null pancreases at week 8 (ESM Fig. 3j). The insulin-to-proinsulin ratio remained remarkably similar between Aldh $1 b 1^{\text {tm1lacZ }}$ null and controls until week 20 (ESM Fig. 3g-i). Total pancreas hormone levels returned to normal at week 20 and this, coupled with the 3.6-fold expansion in beta cell mass at that stage (ESM Figs $3 g, h, j$ and Fig. 4d), implied lower insulin concentration in cells.

ALDH1B1 is not expressed in the fat or skeletal muscle of adult mice, as demonstrated by the lack of detectable $\beta$-galactosidase activity in $A l d h 1 b 1^{\text {tmllacZ }}$ heterozygotes (data not shown). To exclude the possibility that the defects in

glucose homeostasis observed in Aldh $1 b 1^{\text {tmllacZ }}$ null mice are due to secondary defects arising from the liver or other peripheral tissues, we conducted a series of experiments that included IPITTs (ESM Fig. 3d), measurement of glucagon levels in the blood (ESM Fig. 31), IPPTTs and measurement of glucose-6-phosphatase gene transcript levels as indicators of gluconeogenesis (ESM Fig. 3m, n), and measurement of hepatic glycogen stores (ESM Fig. 3m). In all assays, Aldh $1 b 1^{\text {tm1lacZ }}$ null mice behaved similarly to wild-type controls.

Taken together, these findings suggested that the Aldh $1 b 1^{\text {tm1lacz }}$ null mice are glucose intolerant due to islet defects in glucose-stimulated insulin secretion (GSIS).

Aldh $1 b 1^{\text {tm1lacz }}$ null islets are defective in GSIS Aldh $1 b 1^{\text {tmllacZ }}$ null mice are born with islet molecular defects that are expanded in early adulthood. The high insulin content in the pancreases of adult $A l d h 1 b 1^{\text {tmllacZ }}$ null mice at week 8 (ESM Fig. 3g) partially compensated for functional defects and delayed the onset of hyperglycaemia, which became evident from week 12 and worsened progressively with age (Fig. 4e). Therefore, we focused subsequent functional analyses of the islets at week 20. Serum insulin levels were similar 
in Aldh $1 b 1^{\text {tm1lacZ }}$ null and control mice, following a $4 \mathrm{~h}$ fasting period (ESM Fig. 3k) but following a glucose challenge the defects in acute insulin secretion of Aldh $1 b 1^{\mathrm{tm} 1 \mathrm{lacZ}}$ null mice were similar to those detected at week 6 (Fig. $4 \mathrm{~g}$ and ESM Fig. 3c). We then directly assayed the GSIS capacity of islets isolated from $A l d h 1 b 1^{\text {tmllacZ }}$ null mice at week 20. Insulin medium concentration in the basal condition was $79.2 \pm 8.6 \mathrm{pmol} / \mathrm{l}$ in wild-type islets and $87.8 \pm 6.9 \mathrm{pmol} / 1$ in Aldh $1 b 1^{\text {tmllacZ }}$ null islets. Aldh $1 b 1^{\text {tmllacZ }}$ null islets responded very weakly to glucose (Fig. 5a), with insulin concentration reaching $118.8 \pm 5.2 \mathrm{pmol} / 1$ whereas in wild-type islets it reached $1.72 \pm 0.22 \mathrm{nmol} / \mathrm{l}$.

These findings showed that Aldhlb $1^{\text {tmllacz }}$ null islets had severe defects in glucose sensing, stimulus-coupled insulin secretion or both.

Glucose sensing is impaired in the $A l d h 1 b 1^{\text {tm1lacz }}$ null islets We then investigated glucose uptake, glycolytic flux and ATP generation in the Aldh $1 b 1^{\text {tm1lacz }}$ null mutants. Immunostaining for Glut2 (Slc2a2) did not reveal changes in expression at either week 6 or week 20 (ESM Fig. 4 i, j). However, GLP1R immunostaining was severely decreased

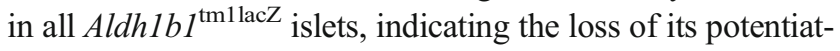
ing effect in glucose uptake (Fig. 5f, g). RNA Seq data showed that expression of $c-m y c$, a central regulator of glycolytic gene expression [35], was strongly repressed and expressions of several genes involved in the glycolytic pathway and genes encoding enzymes diverting glutamine in the tricarboxylic acid cycle were deregulated (Fig. 5e and ESM Table 1). In mammals, low energy levels are reflected by increased AMP:ATP or ADP:ATP ratios and this leads to the activation of AMP-activated protein kinase (AMPK) by phosphorylation [36]. Levels of P-AMPKA in the Aldh $1 b 1^{\text {tmllacZ }}$ null islets were substantially higher than in controls suggesting that null beta cells were energy depleted (Fig. 5i, j). ATP levels, determined by chemiluminescence, were indeed reduced by nearly twofold in isolated Aldh $1 b 1^{\text {tmllacZ }}$ null islets (Fig. 5b). Additionally, a very large number of ribosomal protein genes were downregulated (ESM Fig. 5e and ESM Table 2). This also explains the weak expression of PDX1 and NKX6.1 at the protein level (Fig. 3a-c) despite the upregulation of the corresponding genes (Fig. 2d and ESM Table 1).

Beta cells are vulnerable to sustained oxidative stress due to the low expression of antioxidant enzymes [37]. Control mice maintained or induced expression of several genes involved in protection from and repair of oxidative damage in the transition from $\mathrm{P} 1$ to the adult stage. This induction did not take place in the Aldh $1 b 1^{\text {tmllacZ }}$ null islets (Fig. 5k and ESM Table 1), consistent with the repression of Nfe2l2 (Fig. 2d) [33]. Staining of islets isolated at week 20 with the live ROS indicator CM-H2DCFDA indicated a much higher ROS content in the null islets (Fig. 51, m). Additionally, immunofluorescence for 4-hydroxynonenal, an indicator of excessive oxidation of unsaturated fatty acids, showed that Aldh $1 b 1^{\text {tmllacZ }}$ null islets were more strongly stained (ESM Fig. 4k, 1). Thus, these findings suggested that $A l d h 1 b 1^{\text {tmllacZ }}$ null islets are subject to oxidative stress.

Taken together these data showed that Aldh $1 b 1^{\text {tmllacZ }}$ null islets are energy depleted and exposed to high oxidative load.

Stimulus-coupling secretion is impaired in the Aldh1b1 $^{\text {tm1lacz }}$ null islets We then investigated the expression and function of the constituent components of stimuluscoupling secretion machinery. The RNA Seq data showed that expression of several $\mathrm{K}^{+}$and $\mathrm{Ca}^{2+}$ transporters was misregulated in the Aldh $1 b^{\text {tm1lacZ }}$ islets (ESM Fig. 5b and ESM Table 2). Additionally, there was a strong upregulation of several $\mathrm{K}^{+}$channel genes in Aldh $1 b 1^{\text {tmllacZ }}$ null islets, including Kcnj11, a type 2 diabetes risk factor [38] (Fig. 5n and ESM Table 1), and expression of adenylate cyclases $A d c y 4$ and $A d c y 5$ was repressed (Fig. 5h and ESM Table 1). To determine whether defects from membrane depolarisation and downstream of it contributed to the phenotype, we first stimulated insulin secretion in isolated islets with $100 \mu \mathrm{mol} / 1$ tolbutamide, a $\mathrm{K}^{+}$channel antagonist, in the presence of basal levels of glucose. Following stimulation, the insulin concentration went from $79.2 \pm 8.6 \mathrm{pmol} / \mathrm{l}$ to $13.9 \pm 0.15 \mathrm{nmol} / 1$ in the wild-type islet medium and reached just $3.27 \pm 0.15 \mathrm{nmol} / \mathrm{l}$ in the Aldh $1 b 1^{\text {tmllacZ }}$ null islet medium, suggesting that the efficiency of events starting with $\mathrm{K}^{+}$-mediated membrane depolarisation and leading to insulin secretion was compromised (Fig. 5c).

The L-type voltage-gated $\mathrm{Ca}^{2+}$ channel genes Cacnalc and Cacnald are essential for rodent pancreatic beta cell function $[39,40]$ and polymorphisms in Cacnald have been associated with type 2 diabetes [41]. RNA Seq data showed that $\mathrm{Ca}^{2+}$ channel genes, including Cacnalc and Cacnald, were upregulated in the adult Aldh $1 b 1^{\text {tmllacZ }}$ islets (Fig. 5n and ESM Table 1). We isolated potential $\mathrm{K}^{+}$channel defects by directly stimulating $\mathrm{Ca}^{2+}$ influx in isolated islets with $2 \mu \mathrm{mol} / 1$ of the specific L-type voltage-sensitive $\mathrm{Ca}^{2+}$ channel agonist BayK8644 in the presence of basal levels of glucose. Following stimulation of wild-type islets, insulin concentration in the medium reached $0.58 \pm 0.04 \mathrm{nmol} / 1$ but remained virtually unchanged in the Aldh $1 b 1^{\text {tmllacz }}$ null islets, suggesting that increased expression of voltage-gated $\mathrm{Ca}^{2+}$ channels was not reflected at the protein level and/or that formation of SGs and exocytosis were affected (Fig. 5d). We then followed, by fluorescence, changes in the intracellular $\mathrm{Ca}^{2+}$ concentration in response to glucose stimulation in isolated islets. The average response was reduced in the week $20 A l d h 1 b 1^{\text {tmllacz }}$ null islets (six mice, $n=59$ ) compared with the wild-type controls (four mice, $n=34$ ) and this was attributed to a group of islets (14 out of 59) with very low or negligible response (Fig. 5o, p). This is consistent with the islet heterogeneity in the nulls demonstrated by variable levels of NKX6.1, PDX1 

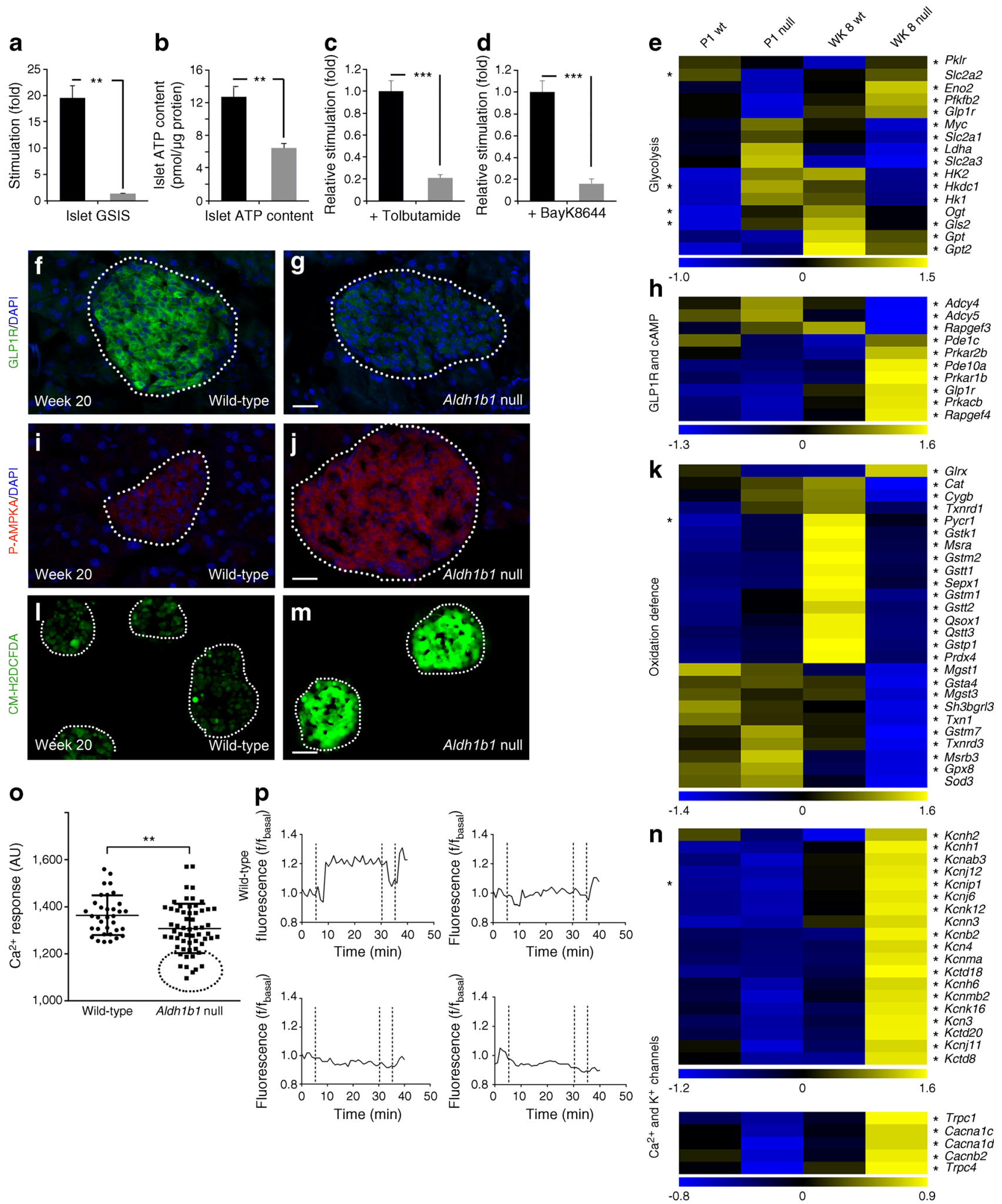

and C-PEP immunostaining (ESM Fig. $4 \mathrm{e}-\mathrm{h}$ ). Thus, reduced $\mathrm{Ca}^{2+}$ mobilisation contributes to, but is not solely responsible for, the observed phenotype.
Regulated insulin exocytosis is the final step of the stimulus-coupled insulin secretion. Underdeveloped or defective insulin SGs lead to compromised insulin secretion and 
4 Fig. 5 Glucose sensing and stimulus-coupling secretion are impaired in Aldh $1 b 1^{\text {tmllacZ }}$ null mice. (a, b) GSIS (a) and total ATP content (b) is reduced by 13 -fold and twofold, respectively, in islets isolated from Aldh $1 b 1^{\text {tmllacz }}$ null mice compared with those isolated from wild-type mice $(n=3)$ (black bars, wild-type; grey bars, null). (c, d) Stimulation of insulin release in isolated islets with tolbutamide (c) or BayK8644 (d) is reduced by fivefold in the $A l d h 1 b I^{\text {tmllacZ }}$ nulls compared with those isolated from wild-type mice $(n=3)$ (black bars, wild-type; grey bars, null). (e-n) Immunofluorescence and gene expression analyses showed that $A l d h 1 b 1^{\text {tm1lacZ }}$ null islets have dramatically reduced GLP1R expression (f, $\mathbf{g}$ ), are energy depleted (i, j) and contain high levels of ROS $(\mathbf{l}, \mathbf{m}) . z$ score heat maps showed misregulated expression of several genes involved in glycolysis (e), GLP1R-mediated cAMP production (h) and oxidation defence $(\mathbf{k})$, as well as $\mathrm{Ca}^{2+}$ and $\mathrm{K}^{+}$ channel genes (n) in the Aldh $1 b 1^{\text {tmllacZ }}$ null islets. $(\mathbf{o}, \mathbf{p})$ Increase in intracellular $\mathrm{Ca}^{2+}$ concentration, calculated as area under the curve in arbitrary units (AU), following glucose stimulation, is reduced in Aldh1b1 ${ }^{\text {tm1lacZ }}$ null islets (o). A subset of Aldh $1 b 1^{\text {tmllacZ }}$ null islets (circled in o) shows weak or absent intracellular $\mathrm{Ca}^{2+}$ mobilisation when compared with a typical wild-type response (wild-type response is shown in the upper left panel of $\mathbf{p}$, the others represent affected islets). Horizontal lines in (o) represent the mean and SD; dotted lines in (p) represent injection time points of stimulation medium (5 min $20 \mathrm{~s}$ ), baseline (35 min $20 \mathrm{~s})$ and $\mathrm{KCl}(40 \mathrm{~min} 20 \mathrm{~s})$. Results are from three to five animals per genotype. At least 25 islets per animal were scored or assayed. Values are means \pm SEM. ${ }^{* *} p<0.01$ and ${ }^{* * *} p<0.001$ for indicated comparisons. Heat maps $(\mathbf{e}, \mathbf{h}, \mathbf{k}, \mathbf{n}),{ }^{*} p_{\text {adj }} \leq 0.05$ : at the left side of the heat map * refers to comparisons at $\mathrm{P} 1$ whereas at the right side it refers to comparisons at WK 8 . Scale bars, $25 \mu \mathrm{m}(\mathbf{g}, \mathbf{j})$ and $80 \mu \mathrm{m}$ (m). WK, week; WT, wild-type

glucose intolerance [42]. RNA Seq data showed an extensive deregulation of genes associated with cytoplasmic vesicle and SG biogenesis, already apparent at P1 and exacerbated at week 8. A large number of genes associated with SG docking, regulated exocytosis and GTPase regulation were misregulated at week 8 (Fig. 6e and ESM Fig. 5c, d, ESM Tables 1 and 2). Accordingly, we examined the numbers and morphology of insulin SGs in beta cells of Aldh $1 b 1^{\text {tmllacZ }}$ null and control mice at week 8 using transmission electron microscopy. Electron-dense dark SGs were scored as mature (type 1) and light-grey SGs as immature (type 2) [43] (Fig. 6a, b). Affected Aldh $1 b 1^{\text {tmllacZ }}$ null beta cells contained a slightly higher total number of SGs but, importantly, the ratio of immature to mature SGs was increased by more than twofold (Fig. 6c, d). Since the insulin-to-proinsulin ratio was not affected in the nulls this was most likely due to changes in their constitution and biogenesis.

Taken together, these data show that the functionality of the stimulus-coupling insulin secretion machinery of Aldh $1 b 1^{\text {tmllacZ }}$ null beta cells is impaired at multiple levels.

Deterioration of glucose homeostasis with age To understand the substantial hyperglycaemia that developed with age, we analysed mice at week 52. Glucose tolerance had further deteriorated and acute insulin secretion was weak and monophasic (ESM Fig. 6 a, b). Energy depletion and oxidative stress were again detected in $A l d h 1 b 1^{\text {tm1lacZ }}$ null islets but not in controls. Additionally, increased cell death was now detected in all null islets but not in controls (ESM Fig. $6 \mathrm{c}-\mathrm{h}$ ). Also, proinsulin processing was now less efficient in the Aldh $1 b 1^{\text {tmllacZ }}$ nulls and pancreas glucagon levels were increased (ESM Fig. 3 i, j). As a result of chronic hyperglycaemia the nulls developed insulin resistance by week 52 (ESM Fig. 3f). Thus, a combination of persisting defects, detected earlier, as well as cell death, defective proinsulin processing and insulin resistance, cause the exacerbation of the phenotype in old age.

\section{Discussion}

Beta cell dysfunction is a clinical hallmark of the progression to type 2 diabetes [1]. Studies in humans and rodents have associated nutrient depletion or environmental insults during fetal growth with increased susceptibility to adult onset of metabolic disease and beta cell dysfunction but little is known about the implicated molecular players [13-15]. The Aldh $1 b 1^{\text {tmllacZ }}$ null mice provide a model whereby early defects in fetal and neonatal stages manifest later in islet functional defects and deterioration of glucose homeostasis, capturing aspects of type 2 diabetes patients. Early defects in null young adult mice (weeks 6-8) are manifested both molecularly and functionally. Similar islet heterogeneity is encountered in all mice examined and therefore the phenotype among mice is relatively uniform. The presence of normal islets mitigates the phenotype.

Since Aldh $1 b 1$ is expressed only in pancreatic progenitors and briefly in newly formed fetal beta cells, the origin of the documented islet defects is embryonic. The relatively mild phenotype could be due to the robust expression of other ALDH genes including mitochondrial ones in the developing pancreas (ESM Table 3). Islet heterogeneity may result because either compensating ALDH genes are not homogeneously expressed in the progenitors or shifting the differentiation window of endocrine cells at an earlier time deprives a subset of differentiating cells from essential signals.

Reduced expression of several transcription factors that play overlapping roles in establishing and maintaining beta cell functionality $[5,6,8-12,27,44]$ was significant at P1 in the islets of $A l d h 1 b 1^{\text {tmllacZ }}$ null mutants whereas misregulation of other beta cell functional components was manifested mostly later. Expression of these transcription factors was subsequently upregulated in the islets of $A l d h 1 b 1^{\text {tm1lacZ }}$ null adults suggesting an adaptive response. The increase in beta cell mass is also such a response but does not address the functional defects arising from the misregulation of essential transcription factors. Thus, misregulation of the beta cell transcription factor network is the primary result of Aldh $1 b 1$ functional inactivation and underlies 

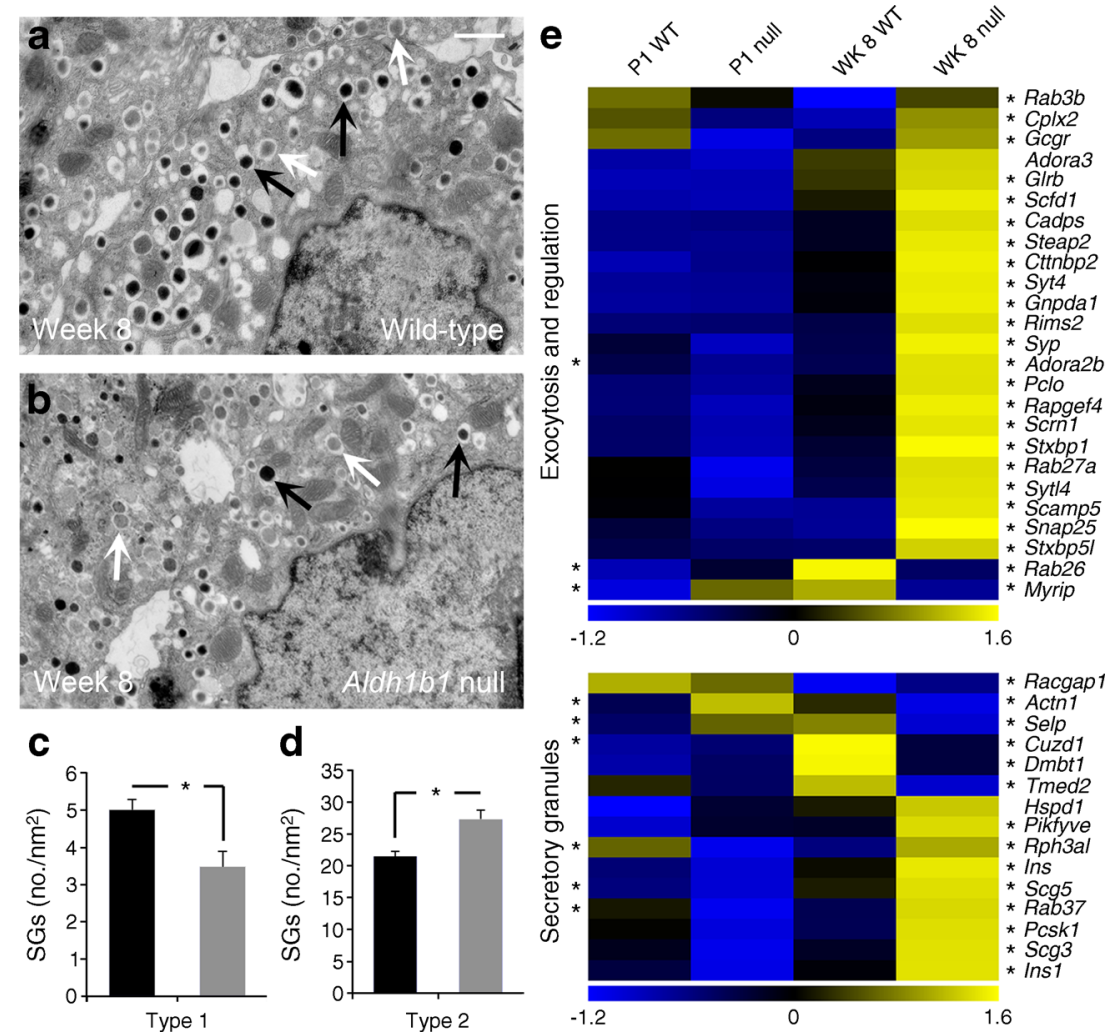

Fig. 6 Immature secretory granules and misregulated exocytosis and SG genes in the Aldh $1 b 1^{\text {tmllacZ }}$ null islets. (a-d) Transmission electron microscopy revealed that affected Aldh $1 b 1^{\text {tm1lacz }}$ null beta cells have $30 \%$ (c) fewer type $1 \mathrm{SGs}$ (mature granules shown by black arrows in $\mathbf{a}, \mathbf{b}$ ) and $22 \%$ (d) more type 2 SGs (immature granules shown by white arrows in a, b). Results are from three animals per genotype and islet cells were scored in double blind experiments for granule number and type (black

bars, wild-type; grey bars, null). (e) $z$ score heat maps showed misregulated expression of several genes involved in SG formation and exocytosis. Values are means \pm SEM. ${ }^{*} p<0.01$ for indicated comparison. Heat map, ${ }^{*} p_{\text {adj }} \leq 0.05$ : at the left side of the heat map * refers to comparisons at $\mathrm{P} 1$ whereas at the right side it refers to comparisons at WK 8. Scale bar, $1 \mu \mathrm{m}$. WK, week; WT, wild-type

the multiplicity of defects in the islets of $A l d h 1 b 1^{\text {tmllacZ }}$ null mice.

Availability of low ROS concentrations appears to be critical for self-renewal of some tissue stem cells [45, 46]. ALDH1B1 activity may participate in ROS level regulation in the pancreatic progenitors and, therefore, the regulation of the timing of lineage commitment. Premature commitment may limit the exposure of progenitors to necessary patterning signals. Alternatively, ALDH1B1 may modulate metabolic processes in the mitochondrion and, therefore, affect the levels of key metabolites necessary for the enzymes employed in epigenetic regulation of gene expression [47]. It has indeed been hypothesised that nutrient availability during fetal growth may lead to epigenetic changes predisposing to diabetes later in life [48]. Metabolomics of pancreatic progenitors and analysis of epigenetic changes in newly formed beta cells may clarify the underlying molecular mechanism.

In summary, the findings suggest that deregulation of the transcription factors that control beta cell specification, maturation and maintenance is the main early effect of Aldhlb1 inactivation and this occurs at the level of progenitor/committed

endocrine cells during development. This has implications for the conversion of pluripotent stem cells into functional mature beta cells and the restoration of dysfunctional beta cells in type 2 diabetes. In addition, the findings indicate that genetic predisposition to type 2 diabetes may arise from mutations in developmental genes, which may not necessarily result in an early postnatal phenotype but manifest later in life.

Acknowledgements We thank M. Gouti (Francis Crick Institute, London), Z. Kanaki and A. Klinakis (BRFAA, Athens) for mouse ES cell culture and blastocyst injections, I. Kasampalidis (BRFAA, Athens) for statistical analysis of the islet size distributions, T. Kurth and S. Kretzschmar (TU Dresden) for EM embedding and sectioning and the personnel of the animal houses at BRFAA and MTZ/TU Dresden for expert animal husbandry. The Aldh1b1 mouse strain used for this research project was created from ES cell clone Aldh1b1_Ae11, generated by the Mouse Biology Program (www.mousebiology.org), and made into ES cells by the KOMP Repository (WWW.KOMP.org) at the University of California Davis.

Funding This work was supported by grants from the European Foundation for the Study of Diabetes (EFSD/LILLY) (AG), the General Secretariat for Research and Technology (ESPA 2011, SYN-1-1496) (Greece) (AG), the Juvenile Diabetes Foundation (Hellas) (AG), the 
German Centre for Diabetes Research (DZD) (AG, SS), the Emmy Noether Program of the German Research Foundation (DFG) (SS), the CRTD - DFG Research Center for Regenerative Therapies Dresden (SS), the Cluster of Excellence and the DFG - SFB/Transregio 127 (SS), the DFG (AD) and the SFB655 of the DFG (AD).

Contribution statement IS and AG conceived and designed the study. All authors were involved with the acquisition, analysis and interpretation of data. AG wrote the manuscript, with critical revision from IS, VA, EN, DA, JS, AM, AD, MS and SS. All authors approved the final version of the paper. IS and AG are the guarantors of this work.

Duality of interest The authors declare that there is no duality of interest associated with this manuscript.

Open Access This article is distributed under the terms of the Creative Commons Attribution 4.0 International License (http:// creativecommons.org/licenses/by/4.0/), which permits unrestricted use, distribution, and reproduction in any medium, provided you give appropriate credit to the original author(s) and the source, provide a link to the Creative Commons license, and indicate if changes were made.

\section{References}

1. Ferrannini E (2010) The stunned beta cell: a brief history. Cell Metab 11:349-352

2. Kesavan G, Sand FW, Greiner TU et al (2009) Cdc42-mediated tubulogenesis controls cell specification. Cell 139:791-801

3. Kopp JL, Dubois CL, Hao E, Thorel F, Herrera PL, Sander M (2011) Progenitor cell domains in the developing and adult pancreas. Cell Cycle 10:1921-1927

4. Johansson KA, Dursun U, Jordan N et al (2007) Temporal control of neurogenin3 activity in pancreas progenitors reveals competence windows for the generation of different endocrine cell types. Dev Cell 12:457-465

5. Brissova M, Shiota M, Nicholson WE et al (2002) Reduction in pancreatic transcription factor PDX-1 impairs glucose-stimulated insulin secretion. J Biol Chem 277:11225-11232

6. Shih DQ, Heimesaat M, Kuwajima S, Stein R, Wright CV, Stoffel $M$ (2002) Profound defects in pancreatic $\beta$-cell function in mice with combined heterozygous mutations in Pdx-1, Hnf- $1 \alpha$, and Hnf$3 \beta$. Proc Natl Acad Sci U S A 99:3818-3823

7. Arda HE, Benitez CM, Kim SK (2013) Gene regulatory networks governing pancreas development. Dev Cell 25:5-13

8. Doyle MJ, Sussel L (2007) Nkx2.2 regulates $\beta$-cell function in the mature islet. Diabetes 56:1999-2007

9. Du A, Hunter CS, Murray J et al (2009) Islet-1 is required for the maturation, proliferation, and survival of the endocrine pancreas. Diabetes 58:2059-2069

10. Gu C, Stein GH, Pan N et al (2010) Pancreatic beta cells require NeuroD to achieve and maintain functional maturity. Cell Metab 11:298-310

11. Hang Y, Yamamoto T, Benninger RK et al (2014) The MafA transcription factor becomes essential to islet $\beta$-cells soon after birth. Diabetes 63:1994-2005

12. Schaffer AE, Taylor BL, Benthuysen JR et al (2013) Nkx6.1 controls a gene regulatory network required for establishing and maintaining pancreatic Beta cell identity. PLoS Genet 9:e1003274

13. Simmons RA, Templeton LJ, Gertz SJ (2001) Intrauterine growth retardation leads to the development of type 2 diabetes in the rat. Diabetes 50:2279-2286
14. Dumortier O, Hinault C, Gautier N, Patouraux S, Casamento V, Van Obberghen E (2014) Maternal protein restriction leads to pancreatic failure in offspring: role of misexpressed microRNA-375. Diabetes 63:3416-3427

15. Thurner S, Klimek P, Szell M et al (2013) Quantification of excess risk for diabetes for those born in times of hunger, in an entire population of a nation, across a century. Proc Natl Acad Sci U S A 110:4703-4707

16. Balber AE (2011) Concise review: aldehyde dehydrogenase bright stem and progenitor cell populations from normal tissues: characteristics, activities, and emerging uses in regenerative medicine. Stem Cells 29:570-575

17. Garaycoechea JI, Crossan GP, Langevin F, Daly M, Arends MJ, Patel KJ (2012) Genotoxic consequences of endogenous aldehydes on mouse haematopoietic stem cell function. Nature 489: 571-575

18. Ioannou M, Serafimidis I, Arnes L et al (2013) ALDH1B1 is a potential stem/progenitor marker for multiple pancreas progenitor pools. Dev Biol 374:153-163

19. Mao P, Joshi K, Li J et al (2013) Mesenchymal glioma stem cells are maintained by activated glycolytic metabolism involving aldehyde dehydrogenase 1A3. Proc Natl Acad Sci U S A 110:8644 8649

20. Rovira M, Scott SG, Liss AS, Jensen J, Thayer SP, Leach SD (2010) Isolation and characterization of centroacinar/terminal ductal progenitor cells in adult mouse pancreas. Proc Natl Acad Sci U S A 107:75-80

21. Serafimidis I, Heximer S, Beis D, Gavalas A (2011) GPCR signaling and S1P play a phylogenetically conserved role in endocrine pancreas morphogenesis. Mol Cell Biol 31:5702-5711

22. Li DS, Yuan YH, Tu HJ, Liang QL, Dai LJ (2009) A protocol for islet isolation from mouse pancreas. Nat Protoc 4:16491652

23. Nguyen LM, Pozzoli M, Hraha TH, Benninger RK (2014) Decreasing Cx36 gap junction coupling compensates for overactive $\mathrm{K}_{\text {ATP }}$ channels to restore insulin secretion and prevent hyperglycemia in a mouse model of neonatal diabetes. Diabetes 63: $1685-1697$

24. Lee SC, Robson-Doucette CA, Wheeler MB (2009) Uncoupling protein 2 regulates reactive oxygen species formation in islets and influences susceptibility to diabetogenic action of streptozotocin. J Endocrinol 203:33-43

25. Taylor BL, Liu FF, Sander M (2013) Nkx6.1 is essential for maintaining the functional state of pancreatic beta cells. Cell Rep 4: $1262-1275$

26. Knoch KP, Bergert H, Borgonovo B et al (2004) Polypyrimidine tract-binding protein promotes insulin secretory granule biogenesis. Nat Cell Biol 6:207-214

27. Ashery-Padan R, Zhou X, Marquardt T et al (2004) Conditional inactivation of Pax6 in the pancreas causes early onset of diabetes. Dev Biol 269:479-488

28. Gannon M, Ables ET, Crawford L et al (2008) pdx-1 function is specifically required in embryonic beta cells to generate appropriate numbers of endocrine cell types and maintain glucose homeostasis. Dev Biol 314:406-417

29. Henseleit KD, Nelson SB, Kuhlbrodt K, Hennings JC, Ericson J, Sander M (2005) NKX6 transcription factor activity is required for $\alpha$ - and $\beta$-cell development in the pancreas. Development 132: 3139-3149

30. Gao T, McKenna B, Li C et al (2014) Pdx1 maintains beta cell identity and function by repressing an alpha cell program. Cell Metab 19:259-271

31. Georgia S, Bhushan A (2004) Beta cell replication is the primary mechanism for maintaining postnatal beta cell mass. J Clin Invest 114:963-968 
32. Goodyer WR, Gu X, Liu Y, Bottino R, Crabtree GR, Kim SK (2012) Neonatal beta cell development in mice and humans is regulated by calcineurin/NFAT. Dev Cell 23:21-34

33. Yagishita Y, Fukutomi T, Sugawara A et al (2014) Nrf2 protects pancreatic beta-cells from oxidative and nitrosative stress in diabetic model mice. Diabetes 63:605-618

34. Singh S, Chen Y, Matsumoto A et al (2015) ALDH1B1 links alcohol consumption and diabetes. Biochem Biophys Res Commun 463:768-773

35. Dang CV, Le A, Gao P (2009) MYC-induced cancer cell energy metabolism and therapeutic opportunities. Clin Cancer Res 15:6479-6483

36. Hardie DG (2015) AMPK: positive and negative regulation, and its role in whole-body energy homeostasis. Curr Opin Cell Biol 33:1-7

37. Robertson RP (2004) Chronic oxidative stress as a central mechanism for glucose toxicity in pancreatic islet beta cells in diabetes. J Biol Chem 279:42351-42354

38. Gloyn AL, Reimann F, Girard C et al (2005) Relapsing diabetes can result from moderately activating mutations in KCNJ11. Hum Mol Genet 14:925-934

39. Jing X, Li DQ, Olofsson CS et al (2005) CaV2.3 calcium channels control second-phase insulin release. J Clin Invest 115:146-154

40. Schulla V, Renstrom E, Feil R et al (2003) Impaired insulin secretion and glucose tolerance in beta cell-selective $\mathrm{Ca}_{\mathrm{V}} 1.2 \mathrm{Ca}^{2+}$ channel null mice. EMBO J 22:3844-3854
41. Reinbothe TM, Alkayyali S, Ahlqvist E et al (2013) The human Ltype calcium channel Cav1.3 regulates insulin release and polymorphisms in CACNA1D associate with type 2 diabetes. Diabetologia $56: 340-349$

42. Suckale J, Solimena M (2010) The insulin secretory granule as a signaling hub. Trends Endocrinol Metab 21:599-609

43. Pictet RL, Clark WR, Williams RH, Rutter WJ (1972) An ultrastructural analysis of the developing embryonic pancreas. Dev Biol 29:436-467

44. Zhang C, Moriguchi T, Kajihara M et al (2005) MafA is a key regulator of glucose-stimulated insulin secretion. Mol Cell Biol 25:4969-4976

45. Ito K, Hirao A, Arai F et al (2004) Regulation of oxidative stress by ATM is required for self-renewal of haematopoietic stem cells. Nature 431:997-1002

46. Shackleton M, Vaillant F, Simpson KJ et al (2006) Generation of a functional mammary gland from a single stem cell. Nature 439:84 88

47. Lu C, Thompson CB (2012) Metabolic regulation of epigenetics. Cell Metab 16:9-17

48. Guenard F, Deshaies Y, Cianflone K, Kral JG, Marceau P, Vohl MC (2013) Differential methylation in glucoregulatory genes of offspring born before vs. after maternal gastrointestinal bypass surgery. Proc Natl Acad Sci U S A 110:11439-11444 